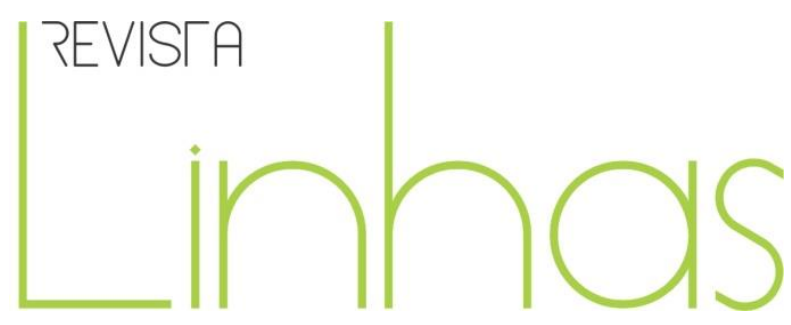

\title{
O PARFOR na Universidade Federal do Oeste do Pará - UFOPA: Análise e apresentação dos resultados
}

\begin{abstract}
Resumo
Este artigo tem como objetivo analisar o Plano Nacional de Formação dos Professores da Educação Básica - PARFOR, caracterizando seu processo de implantação em nível nacional, estadual e regional e apresentar seus principais resultados na Universidade Federal do Oeste do Pará - UFOPA, entre os anos de 2010 e 2019. O PARFOR iniciou no ano de 2009 para atender emergencialmente uma demanda existente de professores em exercício na rede pública de ensino básico e que não possuíam a formação exigida pela Lei de Diretrizes e Bases da Educação Nacional - LDBEN. A metodologia utilizada caracteriza-se como descritiva com enfoque quantitativo e, nos procedimentos de coleta de dados, utilizou-se um levantamento realizado no Sistema Integrado de Gestão de Atividades Acadêmicas - SIGAA/UFOPA, no qual foi gerada uma matriz de dados em que foram aplicados filtros que permitiram a quantificação das informações. Constatou-se que ingressaram 3.816 (três mil, oitocentos e dezesseis) professores/alunos nas 105 turmas abertas na Sede da UFOPA e em seus Campi Regionais e, destes, 78,1\% receberam grau bem acima da média nacional que é de $47,3 \%$. Verificou-se também que a taxa de evasão é condizente com a média nacional e que a maioria dos ingressantes no PARFOR na UFOPA é do gênero feminino e estava na faixa etária de 30 a 39 anos. As informações coletadas permitiram concluir que o PARFOR na UFOPA alcançou resultados expressivos. Esses profissionais, agora com formação adequada, estão aptos a contribuir de maneira expressiva para a melhoria dos indicadores de qualidade da educação em todos os municípios da Região Sudoeste do Estado do Pará.
\end{abstract}

Palavras-chave: Formação de professores; políticas públicas; educação básica.

\section{Para citar este artigo:}

MULLER, Fabiano Hector Lira; DEL PINO, José Claúdio. O PARFOR na Universidade Federal do Oeste do Pará - UFOPA: Análise e apresentação dos resultados. Revista Linhas. Florianópolis, v. 22, n. 49, p. 320-343, maio/ago. 2021.

Fabiano Hector Lira Muller

Universidade do Vale do Taquari UNIVATES - Lajeado/RS - Brasil

fabianohector@hotmail.com

\section{José Claudio Del Pino}

Universidade do Vale do Taquari UNIVATES - Lajeado/RS - Brasil delpinojc@yahoo.com.br 


\title{
PARFOR at the Federal University of Western Pará - UFOPA: Analysis and presentation of results
}

\begin{abstract}
This article aims to analyze the National Training Plan for Basic Education Teachers - PARFOR, characterizing its implementation process at the national, state and regional level and presenting its main results at the Federal University of Western Pará - UFOPA, between the years of 2010 and 2019. PARFOR started in 2009 to respond urgently to an existing demand for teachers working in the public basic education network and who did not have the training required by the Law of Directives and Bases of National Education - LDBEN. The methodology used is characterized as descriptive with a quantitative focus and the data collection procedures used a survey carried out in the Integrated Management System for Academic Activities - SIGAA / UFOPA, in which a data matrix was generated in which filters were applied that allowed the quantification of the information. It was found that 3,816 (three thousand, eight hundred and sixteen) teachers / students entered the 105 classes opened at the Headquarters of UFOPA and its Regional Campuses and, of these, $78.1 \%$ received a degree well above the national average of $47,3 \%$. It was also found that the dropout rate is consistent with the national average and that the majority of those entering PARFOR at UFOPA are female and were between 30 and 39 years old. The information collected allowed us to conclude that PARFOR at UFOPA achieved expressive results. These professionals, now with adequate training, are able to contribute significantly to the improvement of education quality indicators in all municipalities in the Southwest Region of the State of Pará.
\end{abstract}

Keywords: Teacher training; public policy; basic education. 


\section{Introdução}

A temática formação de professores ganhou destaque nas últimas décadas, tanto pelas discussões acadêmicas realizadas sobre o tema, quanto em razão dos programas implantados e das mudanças que ocorreram no país. Entre elas, destaca-se o sistema de formação inicial e continuada de professores, incluindo-se nesse contexto a formação em serviço, possibilitando a esses educadores uma formação com a oportunidade de reflexão sobre a sua própria prática, na medida em que eles já atuam como docentes.

Os professores são "elementos insubstituíveis não só na promoção das aprendizagens, mas também na construção de processos de inclusão que respondam aos desafios da diversidade e no desenvolvimento de métodos apropriados" (NÓVOA, 2009, p. 12). Investir na formação do educador significa contribuir com a abertura de perspectivas de melhoria da educação em sua totalidade. O Plano Nacional de Formação dos Professores da Educação Básica - PARFOR foi implantado no ano de 2009, para atender emergencialmente a demanda existente de professores da rede pública de ensino básico, que não possuíam formação de nível superior e "igualar as oportunidades de formação aos profissionais do magistério em Instituições Públicas de Educação Superior com o regime de colaboração da União, dos Estados, Distrito Federal e os municípios" (BASTOS; ZANARDINI, 2014, p. 19), e com isso garantir que os docentes em exercício possuíssem a formação exigida pela Lei de Diretrizes e Bases da Educação Nacional.

Este estudo se propõe a analisar o Plano Nacional de Formação dos Professores da Educação Básica - PARFOR, caracterizando seu processo de implantação em nível nacional, estadual e regional, e apresentar seus principais resultados na Universidade Federal do Oeste do Pará - UFOPA, entre os anos de 2010 e 2019. Este é um recorte da dissertação do Mestrado em Ensino intitulada "A implantação do PARFOR/UFOPA no município de Itaituba/PA: indicadores e resultados", apresentado no Programa de PósGraduação em Ensino (PPG Ensino) da Universidade do Vale do Taquari - Univates, em Lajeado - Rio Grande do Sul. 


\section{Percurso metodológico}

Realizou-se um levantamento bibliográfico com o intuito de possibilitar uma imersão na temática pesquisada. Foram selecionados livros, periódicos, dissertações, teses, manuais, relatórios e leis para dar a base teórica da pesquisa, podendo ser destacados Bastos (2015), Vasconcelos (2016), Costa (2017), Brasil (2014, 2017). Foi necessária uma pesquisa documental nos dados da Sinopse Estatística da Educação Básica do INEP/MEC, na base de dados do IBGE e em relatórios de gestão do PARFOR da Capes da UFPA e da UFOPA.

Esta investigação científica é de natureza descritiva e possui um enfoque quantitativo que, para Marconi e Lakatos (2018, p. 296), "se volta para descrição, previsão e explicação, bem como para dados mensuráveis e observáveis". Com o intuito de analisar a implantação do PARFOR na UFOPA foi necessário fazer um levantamento no Sistema Integrado de Gestão de Atividades Acadêmicas - SIGAA da Universidade Federal do Oeste do Pará - UFOPA, no qual foi gerada uma Matriz de Dados por meio da consulta detalhada de discentes em que a delimitação era a forma de ingresso na Universidade conforme detalhamento: Login no SIGAA/UFOPA> Graduação> Consultas> Consulta geral de discentes> Selecionar forma de ingresso "Processo Seletivo Plataforma Freire"> Buscar.

A pesquisa no SIGAA da UFOPA permitiu que fosse gerado um arquivo CSV, que é um arquivo de valores separado por vírgula e que pode ser aberto como uma planilha em programas como o Excel. Nessa matriz de dados foram aplicados filtros que permitiram a quantificação das informações como: ano de ingresso, cidade, curso escolhido, faixa etária e gênero.

A organização das informações na pesquisa "implica uma ordenação lógica dos dados coletados, levando em conta sua importância e evidência" (PADUA, 2012, p. 83). Foram estabelecidas as relações existentes entre os dados da pesquisa. Agruparam-se os elementos principais com o intuito de estabelecer relações destes com a temática discutida no referencial teórico, cuja ação possibilitou detectar e interpretar os pontos de convergência e divergência da pesquisa e possibilitou a discussão das informações. 
Para finalizar a parte da análise, foi necessário o tratamento estatístico dos dados da pesquisa. Os relatórios gerados no SIGAA da UFOPA, bem como os dados da Sinopse Estatística da Educação Básica do INEP/MEC dos anos 2009 a 2018, juntamente com a matriz de dados gerada no SIGAA, permitiram a análise e apresentação dos principais resultados do PARFOR na UFOPA.

\section{O PARFOR como política pública de Estado}

Com base nas informações do Instituto Nacional de Estudos e Pesquisas Educacionais - INEP, no documento intitulado como Censo do Professor 1997: perfil dos docentes de Educação Básica, no ano de 1997, no Brasil havia 1.617.611 (um milhão, seiscentos e dezessete mil, seiscentos e onze) professores atuando na Educação Básica, dos quais 113.867 (cento e treze mil, oitocentos e sessenta e sete) possuíam apenas o primeiro grau (até oitava série) completos e 785.637 (setecentos e oitenta e cinco mil, seiscentos e trinta e sete) possuíam o segundo grau completo (INEP, 1999).

O levantamento realizado pelo Ministério da Educação - MEC e disponível na Proposta de Diretrizes para a Formação Inicial de Professores da Educação Básica, em cursos de nível superior, mostrou que, até os anos 2000, havia “[...] uma enorme distância entre o perfil de professor que a realidade atual exige e o perfil de professor que a realidade até agora criou" (BRASIL, 2000, p. 12). Isso mostrava a necessidade de investimento na formação dos profissionais docentes e levantava a discussão para medidas que os governos deveriam tomar para mudar esse cenário.

No início do século XXI, houve um intenso debate no âmbito nacional com vistas a uma reformulação do Sistema Educacional, que culminou com a criação de novas instituições de ensino, entre elas Universidades e Institutos Federais. Ocorreram mudanças importantes no sistema de formação inicial e continuada de professores, incluindo-se nesse contexto a formação em serviço, que era uma forma de garantir continuidade desse profissional no seu trabalho nas respectivas redes de ensino e ofertar a esse professor a possibilidade de obter uma graduação.

A partir do ano 2002, com a promulgação das Diretrizes Curriculares Nacionais para a Formação de Professores - DCN, foram feitas as primeiras adaptações nos 
currículos de formação docente e das diretrizes curriculares para cursos de licenciatura. Em abril de 2007, foi promulgado o Decreto 6.094/2007, que dispunha sobre a implementação do Plano de Metas Compromisso Todos pela Educação, pela União Federal, em regime de colaboração com Municípios, Distrito Federal e Estados, e a participação das famílias e da comunidade, mediante programas e ações de assistência técnica e financeira, visando à mobilização social pela melhoria da qualidade da educação básica.

Ainda em 2007, foi lançado o Plano de Desenvolvimento da Educação: razões, princípios e programas. O PDE foi um conjunto de programas que visava a melhorar a educação no Brasil em todas as suas etapas e tinha como foco principal a formação de professores e a valorização dos profissionais da educação. Esse Plano estava sustentado em seis pilares: 1) visão sistêmica da educação, 2) territorialidade, 3) desenvolvimento, 4) regime de colaboração, 5) responsabilização e 6) mobilização social, tendo o prazo de quinze anos para ser completado, porém, acabou descontinuado antes desse período.

Considerando esse cenário de mudanças no rumo da educação básica no Brasil, com o surgimento de ações voltadas à formação de professores, entre eles os docentes em serviço, Costa (2017, p. 12) informa que “[...] com a aprovação da Lei n 11.502, de 11 de julho de 2007, foram modificados os termos da Lei $n^{\circ} 8.405$, de 09 de janeiro de 1992, ampliando as competências da Coordenação de Aperfeiçoamento de Pessoal de Nível Superior - Capes”. Com isso, foram conferidas à Capes as atribuições de induzir e fomentar a formação inicial e continuada de profissionais da educação básica e estimular a valorização do magistério em todos os níveis e modalidades de ensino, ações essas que foram executadas por meio da Diretoria de Educação Básica Presencial - DEB, que tinha como missão "promover ações voltadas para a valorização do magistério por meio da formação de professores" (DEB, 2013, p. 05). Nessa linha de raciocínio, existe esta sequência de fatos:

Em janeiro de 2009 é publicado o Decreto n. 6.755 que institui a Política Nacional de Formação de Profissionais do Magistério da Educação Básica a qual trouxe a prerrogativa de respaldar a atuação da Capes no fomento a programas de formação inicial e continuada (BASTOS, 2015). De acordo com este Decreto, seus objetivos seriam cumpridos por meio da criação dos Fóruns Estaduais Permanentes de Apoio à Formação Docente tendo a função de elaborar planos 
estratégicos para materializar o regime de colaboração entre a União, os Estados, o Distrito Federal e os Municípios no desenvolvimento das ações formativas dos profissionais da educação.

No Decreto $n^{\circ}$ 6.755/2009, em seu art. 11, estavam explicitadas as ações de fomento da Capes, com destaque para o inciso III, que possibilita a criação do PARFOR para atender essa demanda, a saber:

III - Oferta emergencial de cursos de licenciaturas e de cursos ou programas especiais dirigidos aos docentes em exercício a pelo menos três anos na rede pública de educação básica, que sejam:
a) graduados não licenciados;
b) licenciados em área diversa da atuação docente; e
c) de nível médio, na modalidade Normal; (BRASIL, 2009, p. 4, art. 11)

Assim, o PARFOR surgiu como um programa emergencial instituído para atender o que está previsto no art. 11, inciso III do Decreto $n^{\circ}$ 6.755, de 29 de janeiro de 2009, com o objetivo principal de garantir que os professores em exercício na rede pública de educação básica possuam a formação exigida pela Lei de Diretrizes e Bases da Educação Nacional - LDBEN, o qual deveria ser executado em regime de colaboração entre a Capes, os Estados, os Municípios, o Distrito Federal e as Instituições de Educação Superior (BRASIL, 2014; BASTOS, 2015; COSTA, 2017).

O PARFOR se estruturou nos Estados da Federação por meio de Acordos de Cooperação Técnica - ACTs, firmados entre a Capes e as Secretarias Estaduais de Educação ou órgão equivalente. As Instituições de Ensino Superior se articularam ao PARFOR por meio de assinatura de Termo de Adesão ao Acordo de Cooperação Técnica:

O Programa, diferentemente dos cursos de formação de professores oferecidos com recursos do Fundef, está sob a responsabilidade direta do governo federal. Tem ainda como objetivo garantir que os professores em exercício na rede pública da educação básica obtenham a formação exigida pela legislação, sendo, para tal, constituídas turmas especiais, exclusivas, para atender aos professores em exercício. (MAUÉS; CAMARGO, 2012, p. 163)

O público-alvo do PARFOR eram professores da rede municipal ou estadual que estivessem atuando no Ensino Básico e que: a) não tivessem formação superior ou que, mesmo tendo essa formação, quisessem realizar curso na área/disciplina ou etapa em que 
atuavam em sala de aula; b) atuassem em área distinta da sua formação inicial; c) fossem graduados, mas não possuíssem grau em licenciatura. Caso houvesse vagas remanescentes, essas poderiam ser preenchidas pelos profissionais em serviço, cadastrados no Educacenso ${ }^{1}$ que estivessem atuando nas funções de auxiliar/assistente educacional ou profissional/monitor de atividade complementar.

De acordo com o Manual Operativo do PARFOR, a oferta de cursos seria em três modalidades:

I. Licenciatura - para docentes ou tradutores e intérpretes de Libras em exercício na rede pública da educação básica que não tenham formação superior ou que mesmo tendo essa formação se disponham a realizar curso de licenciatura na etapa/disciplina em que atua em sala de aula;

II. Segunda licenciatura - para professores que estejam em exercício há pelo menos três anos na rede pública de educação básica e que atuem em área distinta da sua formação inicial, ou para profissionais que atuam como tradutor intérprete de Libras;

III. Formação Pedagógica - para docentes graduados não licenciados que se encontram no exercício da docência ou que atuem como tradutor intérprete de Libras na rede pública da educação básica. (BRASIL, 2014, p. 1)

A forma de ingresso no Plano Nacional de Formação dos Professores da Educação Básica era por meio do cadastramento do currículo e da realização de uma pré-inscrição no ambiente virtual da Plataforma Paulo Freire. As pré-inscrições realizadas pelos professores/alunos ${ }^{2}$ eram validadas pela Secretaria de Educação à qual estivessem vinculados. Após esse processo, as inscrições validadas eram disponibilizadas para que as Instituições de Ensino Superior realizassem a matrícula nas licenciaturas ofertadas. As ações desenvolvidas pelo PARFOR estiveram, inicialmente, restritas às Universidades Públicas e em um primeiro momento tiveram a adesão de 21 Estados da Federação; porém, a demanda mostrou-se maior do que a quantidade de vagas ofertadas:

\footnotetext{
1 Educacenso é uma ferramenta do Ministério da Educação que permite obter dados individualizados de cada estudante, professor, turma e escola do país, tanto das redes públicas (federal, estaduais e municipais) quanto da rede privada. A partir dos dados do Educacenso, é calculado o Índice de Desenvolvimento da Educação Básica (Ideb) e planejada a distribuição de recursos para alimentação, transporte escolar e livros didáticos, entre outros (http://portal.mec.gov.br).

${ }^{2}$ Será utilizada a expressão professor/aluno para designar o discente do PARFOR, uma vez que o requisito para que este ingressasse no Programa era que fosse professor da rede pública de educação básica municipal ou estadual.
} 
[...] as 106 Instituições de Educação Superior (IES) públicas (35 estaduais e 71 federais) que aderiram ao PARFOR até fevereiro de 2010, se mostraram insuficientes para atender ao contingente de professores por formação inicial presencial. Houve necessidade de readequar 0 programa, que passou a incluir as instituições superiores comunitárias, filantrópicas e confessionais. (MAUÉS; CAMARGO, 2012, p. 164)

No ano de 2012, o Decreto $n^{\circ}$ 7.692, de 2 de março, alterou o nome da Diretoria de Educação Básica Presencial para Diretoria de Formação de Professores da Educação Básica, mantendo-se a sigla DEB. Com base no Relatório de Gestão do PARFOR dos anos de 2009 a 2013, publicado pela DEB no ano de 2013: "entre 2009 e 2013, foi ofertado no PARFOR um total de 244.065 vagas. Deste total 70,09\% foram de cursos de Primeira Licenciatura, 26,59\% de Segunda Licenciatura e 3,32\% de Formação Pedagógica" (DEB, 2013, p. 40).

O Relatório de Gestão do exercício de 2016 da Capes expõe que "no período 2009 2016 matricularam-se no PARFOR, 94.247 professores. Desse total, 34.549 já se formaram e 36.871 estão cursando" (BRASIL, 2017, p. 101). A oferta de cursos de licenciatura oferecidos pelo PARFOR poderia ser na modalidade presencial e a distância. Na modalidade presencial, sua oferta ficaria sob a responsabilidade das Instituições de Ensino Superior - IES e na modalidade a distância, sob a responsabilidade da Universidade Aberta do Brasil - UAB.

Vale destacar que o foco desta pesquisa é o PARFOR na modalidade presencial; logo, levará em consideração as informações gerais do Plano para dar suporte ao trabalho; todavia, devido às limitações do estudo, não irá aprofundar a discussão em torno das informações do PARFOR na modalidade a distância.

\section{O PARFOR na Amazônia brasileira - implantação no Estado do Pará}

É preciso ter cuidado para não olhar da mesma forma a implantação do Plano Nacional de Formação de Professores da Educação Básica - PARFOR nas demais Regiões do país. Devem-se levar em consideração as particularidades regionais, o fator amazônico e o contexto educacional em que os professores do Ensino Básico - público-alvo desta pesquisa - atuam: 
A Região Norte e seus Estados são onde as políticas públicas devem ser analisadas em sua dinâmica, isto é, não devem ser enfocadas linearmente. E o processo de instalação, por sua vez, deve ser visto também como uma construção e reconstrução da política, capaz de gerar aprendizados e reordenamentos. (BASTOS, 2015, p. 25)

Existe um silêncio de séculos nos livros quando se trata do desenvolvimento da Região Amazônica. Historicamente, é uma região à margem do contexto nacional em termos político, econômico, educacional, sendo habitada por comunidades tradicionais e que tem na exploração mineral e vegetal a sua principal fonte de riqueza e, consequentemente, de impactos:

Desde o processo de colonização, a história da Amazônia foi diferenciada das demais regiões. Portanto, não surpreende que, na ausência de políticas públicas adequadas ao longo da história, as demandas regionais em educação e ciência sejam mais evidentes que na maioria do país. (PARÁ, 2009, p. 3)

Assim, faz-se necessário um olhar diferenciado para se perceber que o desenvolvimento dessa Região não seguiu os mesmos padrões do que ocorreu em outros locais. Essas orientações são validadas ao se fazer uma simples reflexão a respeito do quantitativo de professores/alunos atendidos pelo programa PARFOR nas Regiões do país: “A região Norte lidera o ranking do número de matrículas efetuadas com o percentual de $48,86 \%$, seguida da Nordeste com $38,18 \%$, o Sul com $7,76 \%$, o Sudeste com 3,81\% e o Centro-Oeste com 1,38\%" (DEB, 2013, p. 41). Essa visão geral mostra o quão antagônico é o cenário educacional no Brasil.

Considerando isso, faz-se necessário um "recorte" dessa realidade para que não se criem ideias equivocadas acerca da implantação do PARFOR, em que a simples comparação com o que aconteceu nas demais Regiões do país não contempla todos os fatores envolvidos.

Para Vasconcelos (2016, p. 31), a Região Norte do Brasil tem dificuldade em “[...] atrair profissionais formados, interessados em residir no interior do Estado e/ou formar professores nos lugares mais afastados dos centros urbanos, que tornam a existência de professores leigos uma prática comum". A dificuldade da efetivação regional das políticas públicas pensadas em âmbito nacional é um fator determinante para que algumas ações 
não alcancem os resultados esperados. Até recentemente, cursos de graduação eram oferecidos somente nas capitais e em poucas cidades dos estados, o que acarreta em uma quantidade insuficiente de profissionais para exercer a docência, principalmente em cidades do interior.

Com relação à temática formação de professores, tratando-se especificamente sobre o Estado do Pará, no ano de 2006 - como parte de uma política nacional para a formação de professores que atuam na Educação Básica e com o intuito de minimizar essa problemática dos profissionais atuando na Educação Básica sem formação de nível superior -, foi criado e assinado o protocolo que ficou conhecido como o Protocolo Seduc - IES, que tinha o objetivo de formular proposições e desenvolver ações de modo a promover a melhoria da qualidade da Educação Básica das redes públicas de ensino no Estado do Pará (PARÁ, 2009).

Em 2008, como uma das medidas estratégicas visando a melhorar os indicadores da Educação Básica no Estado, foi elaborado o Plano de Formação Docente do Estado do Pará. O Plano tinha o objetivo de capacitar 40 mil professores no Pará cuja formação não atendia as exigências da Lei $n^{\circ}$ 9.394/1996. O Plano previa a formação continuada de professores da Educação Básica, incluindo pós-graduação (lato e stricto sensu). Constavam como mobilizadores do processo: a União Nacional dos Dirigentes Municipais de Educação do Estado do Pará - Undime/PA e o Protocolo Seduc - IES, que era constituído pelas Instituições Públicas de Ensino Superior do Estado do Pará e também pela Secretaria de Estado de Educação - Seduc.

Essa organização possibilitou a criação do Plano de Formação Docente do Estado do Pará, que foi a base para implantação efetiva do Plano Nacional de Formação de Professores da Educação Básica - PARFOR no Estado. Esses órgãos/entidades parceiro(as) passavam a ter como responsabilidade a atribuição de:

Implantar, organizar e presidir o Fórum Estadual Permanente de Apoio à Formação Docente - Forprof-PA, nos termos do $\S 1^{\circ}$, do Artigo $4^{\circ}$, do Decreto $n^{\circ}$ 6.755, de 29 de janeiro de 2009, presidido pelo Secretário de Estado de Educação que delegou ao Centro de Formação dos Profissionais de Educação Básica do Estado do Pará - Cefor, a responsabilidade de se encarregar da realização do planejamento, acompanhamento, controle e avaliação do PARFOR em todo o Estado do Pará. (COSTA, 2017, p. 19-20) 
A meta estabelecida pelo Plano de Formação Docente do Estado do Pará era de formar 40 mil professores. Conforme dados da Sinopse da Educação Básica do INEP/MEC, o número de professores da Educação Básica por escolaridade no Estado do Pará no ano de 2009 era de 39.737 (trinta e nove mil, setecentos e trinta e sete) professores (PARÁ, 2009). O PARFOR, neste caso, tornou-se o principal expoente no processo, com o intuito de acabar com os profissionais atuando sem a devida formação exigida pela LDBEN.

As Instituições Públicas de Ensino Superior do Estado do Pará ofereceram cursos de Licenciatura em todo o território paraense em regime de colaboração com o Estado e Municípios. De acordo com Kitamura e Silva (2015), no ano de 2015, eram 146 (cento e quarenta e seis) IES (públicas e privadas) instaladas na Região Norte, o que correspondia a 6\% do total das 2.391 existentes no Brasil. Dessas, apenas 26 (vinte e seis) eram públicas. No Estado do Pará eram 06 (seis) as Instituições Públicas de Ensino Superior, e todas ofereceram cursos presenciais do PARFOR entre os anos de 2009 e 2015, a saber:

- Instituto Federal de Educação, Ciência e Tecnologia do Pará - IFPA;

- Universidade do Estado do Pará - UEPA;

- Universidade Federal do Oeste do Pará - UFOPA;

- Universidade Federal do Pará - UFPA;

- Universidade Federal Rural da Amazônia - UFRA;

- Universidade Federal do Sul e Sudeste do Pará - UNIFESSPA.

Assim, do segundo semestre de 2009 até 2015 foram realizados 07 (sete) processos seletivos para ingresso no PARFOR, os quais habilitaram aproximadamente 22 mil professores/alunos para cursarem as 27 (vinte e sete) licenciaturas ofertadas pelas instituições públicas de ensino superior paraenses parceiras do processo, nas diferentes cidades do Estado. De acordo com Vasconcelos:

O PARFOR representa o reconhecimento da importância da formação de professores para a qualidade da educação. É também um meio das universidades federais se fazerem presentes em mais municípios, principalmente os mais distantes, os quais representam, muitas vezes, áreas onde a educação se realiza em condições mais difíceis. A ideia de a formação ir até o local que se necessita dela representa ainda sensibilidade com o contexto socioambiental brasileiro, pois, por vezes, 
razões econômicas, políticas, culturais ou ambientais terminam por dificultar o sonho de muitos brasileiros de continuar a estudar, especialmente em níveis mais elevados de ensino. (VASCONCELOS, 2016, p. 106)

Mostra-se, assim, a importância do regime de colaboração no âmbito do Plano de Formação Docente do Estado do Pará, pois foi a partir disso que houve a possibilidade de as Universidades saírem para além de seus muros e atenderem a cidades e lugarejos sem Campus instalado e onde não havia perspectiva de implantação de cursos públicos de graduação:

O desbravamento da floresta pelo ensino superior e a descentralização do mesmo pelo interior do Pará, no contexto real, significou uma unidade política na qual alicerçou uma construção social dependente de alianças com uma interlocução entre os diferentes grupos sociais que, por meio de acordos entre seus membros, unificam-se quanto aos princípios, valores e normas, traçando, assim, os objetivos a serem alcançados pela comunidade frente aos anseios que se concretizam. (CARVALHO, 2014, p. 74)

Para que os cursos do PARFOR pudessem ocorrer, os municípios polo deveriam oferecer a infraestrutura necessária para o seu funcionamento e as Instituições Públicas de Ensino Superior eram responsáveis pelos professores para atuarem nessas turmas. Essa foi uma estratégia que possibilitou amplo alcance do PARFOR no Estado do Pará que, além dos Campi, possuíam Polos e Núcleos funcionando em diversas cidades do interior do Estado. Nesse sentido, Vasconcelos afirma que:

A universidade precisa pensar a formação de professores a partir da consideração dos sujeitos e de suas problemáticas durante 0 desenvolvimento dos cursos ofertados. Não basta levar, transferir, entregar ou depositar conhecimentos científicos em comunidades amazônicas por meio de cursos de formação. É necessário conhecer e refletir criticamente sobre a realidade vivenciada e compartilhada com os sujeitos que ali vivem para que se busque transformações que colaborem com a melhoria das condições deste cenário. (VASCONCELOS, 2016, p. 39)

Portanto, investir na formação dos profissionais que atuam na Educação Básica significa contribuir com abertura de perspectivas de melhoria da educação na sua totalidade. Afinal, essa ação permite aos docentes uma formação com a oportunidade de 
reflexão sobre a sua própria prática, na medida em que eles já atuam no Ensino Básico. Também é um cenário de possibilidades, uma vez que respeita e considera as peculiaridades e especificidades de sua realidade regional e educacional.

\title{
O PARFOR na Universidade Federal do Oeste do Pará - UFOPA
}

A UFOPA foi criada pela Lei $n^{\circ} 12.085$, de 5 de novembro de 2009. Foi a primeira Instituição Federal de Ensino Superior com sede no interior de um estado da Amazônia brasileira. Sua sede fica no município de Santarém/PA e tem Campi nas cidades de Alenquer, Itaituba, Juruti, Monte Alegre, Óbidos e Oriximiná. Sua criação se deu a partir da política que instalou o Programa de Expansão das Universidades Federais, do Programa de Apoio aos Planos de Reestruturação e Expansão das Universidades Federais (REUNI) e do acordo de cooperação técnica firmado entre o Ministério da Educação (MEC) e a Universidade Federal do Pará (UFPA), com o objetivo de ampliar o ensino superior na região amazônica:

\begin{abstract}
A UFOPA resultou da incorporação do Campus da UFPA em Santarém e da Unidade Descentralizada Tapajós da Universidade Federal Rural da Amazônia (UFRA), unidades onde eram desenvolvidas atividades acadêmicas das duas IFES na região Oeste Paraense. A UFOPA assimilou outras unidades da UFPA e da UFRA para a instalação dos Campi de Alenquer, Itaituba, Juruti, Monte Alegre, Óbidos e Oriximiná. Em Santarém, a UFOPA mantém suas atividades em três unidades: a Unidade Rondon, localizado no bairro Carnaval (antigas instalações da UFPA), e a Unidade Tapajós, localizado no bairro Salé (antigas instalações da UFRA) e a Unidade Amazônia, localizada no Bairro de Fátima (antigas instalações do Hotel Boulevard). (COSTA, 2017, p. 14)
\end{abstract}

Em 09 de julho de 2010, na edição $n^{\circ} 130$ do Diário Oficial da União, por meio do processo no 23038.004959/2010-72, a Coordenação de Aperfeiçoamento de Pessoal de Nível Superior - CAPES, formalizou a adesão da UFOPA ao Acordo de Cooperação Técnica com vistas à implantação do Plano Nacional de Formação dos Professores da Educação Básica (PARFOR) destinado a atender a demanda de profissionais das redes públicas estadual e municipal: 
A primeira etapa de funcionamento do PARFOR na UFOPA foi garantida a partir da assinatura do Termo de Cooperação Simplificado, firmado em 15 de julho de 2010, com verbas destinadas ao deslocamento dos professores, visando ao pagamento de diárias e passagens. Em 23 de novembro desse mesmo ano, um novo Termo de Cooperação Aditivo é assinado, visando a oferecer suporte didático para sistematizar melhor os conteúdos trabalhados em sala de aula e para manter a limpeza e higienização das escolas onde os cursos do PARFOR funcionam no Estado do Pará. Em 15 de julho de 2011, mais um Termo Aditivo de Cooperação é assinado entre a CAPES e a UFOPA, com vigência prevista para 31 de dezembro de 2014, com a destinação de recursos às turmas já iniciadas e às novas turmas a serem implantadas ao longo de quatro anos, compreendidos entre os anos de 2011-2014. (BARRETO; COLARES, 2017, p. 312)

O PARFOR foi instalado efetivamente na Instituição no ano de 2010, com a abertura das primeiras turmas na modalidade Presencial Primeira Licenciatura, para atender 08 (oito) municípios-polos do Oeste do Estado do Pará, distribuídos da seguinte forma: a Sede na cidade de Santarém, 06 (seis) Campi (Itaituba, Oriximiná, Óbidos, Juruti, Monte Alegre e Alenquer) e 01 (um) Núcleo na cidade de Almeirim. As turmas funcionaram de maneira intervalar com calendário definido pelo Fórum Estadual do PARFOR no Pará e que era seguido por todas as IES do Estado.

Geralmente as aulas eram divididas em quatro etapas, duas abrangendo os meses de janeiro/fevereiro e julho/agosto, com mais dois encontros curtos nas entre etapas (uma semana de aula) nos meses de maio e novembro, destinados principalmente para as disciplinas de Estágio e TCC. Nas duas etapas longas eram ofertadas as disciplinas que compõem a estrutura curricular de cada curso, atendendo ao fluxograma semestral ofertado pela UFOPA.

A Universidade ofertou 05 (cinco) cursos na Sede e em seus Campi e Núcleo, os quais foram encaminhados para análise e aprovação dos Colegiados Institucionais e submetidos a processos de avaliação do Ministério da Educação, sendo 04 (quatro) na modalidade Licenciatura Integrada e 01 (um) na modalidade Licenciatura Plena, a saber:

- Licenciatura Integrada em História e Geografia;

- Licenciatura Integrada em Matemática e Física;

- Licenciatura Integrada em Biologia e Química; 
- Licenciatura Integrada em Letras Português e Inglês;

- Licenciatura em Pedagogia.

A UFOPA foi a única Instituição de Ensino Superior a oferecer cursos no PARFOR na modalidade integrada; nas demais IES do restante do país foram oferecidos cursos específicos em uma única área de formação. Todos tinham a duração de nove semestres, em função de o primeiro ser destinado às disciplinas do Centro de Formação Interdisciplinar - $\mathrm{CFI}^{3}$ com as disciplinas: Origem e Evolução do Conhecimento; Estudos Integrativos da Amazônia; Sociedade, Natureza e Desenvolvimento; Lógica, Linguagem e Comunicação; Seminários Integradores; e Interação na Base Real.

As disciplinas destinadas ao CFI eram obrigatórias em todos os cursos da UFOPA, tanto nos extensivos quanto nos intensivos na Sede, nos Campi Regionais e no Núcleo. Sua oferta era de natureza interdisciplinar e se constituía em conteúdos obrigatórios, comuns para o conjunto dos cursos oferecidos pela universidade e tratavam questões contemporâneas e de natureza global a partir do contexto amazônico.

Na Sede da UFOPA, a coordenação ficava a cargo da Coordenação Geral Institucional do programa e dos Coordenadores de Curso. Nos Campi Regionais e no Núcleo, a coordenação funcionava sob a responsabilidade de um Coordenador Local, que no município representaria o PARFOR e deveria realizar a mediação entre a Coordenação Geral Institucional, os Coordenadores de Cursos, os professores que trabalham no Programa e os professores/alunos.

Entre os anos de 2010 e 2019, a Coordenação Geral do PARFOR na UFOPA foi desempenhada por alguns professores que compõem o quadro de docentes efetivos da Universidade, a saber: Prof. Dra. Terezinha de Jesus Dias Pacheco, Prof. Dra. Honorly Kátia Mestre Corrêa, Prof. Dra. Maria de Fátima Sousa Lima, Prof. Dra. Ednéa do Nascimento Carvalho, Prof. Dra. Maria Raimunda Santos da Costa, Prof. Dra. Ediene Pena Ferreira, Prof. Dr. Edivaldo da Silva Bernardo.

Nos Campi regionais e no Núcleo de Almeirim, o funcionamento das turmas ocorreu nas Unidades da própria UFOPA ou em locais cedidos pelas Secretarias de

3 O Centro de Formação Interdisciplinar - CFI é a unidade acadêmica da UFOPA responsável pela oferta inicial do primeiro semestre de ensino para todos os alunos que tiverem acesso à Universidade. (http://www.ufopa.edu.br/cfi/). 
Educação do Estado ou dos Municípios. Nas localidades em que havia Campus da Universidade, um servidor efetivo exerceu a função de coordenador local e, no Núcleo universitário que funcionou na cidade de Almeirim, uma servidora da secretaria municipal de educação foi designada para essa função.

O funcionamento do PARFOR na UFOPA ocorreu nos prédios próprios da Universidade apenas nos Campi das cidades de Óbidos e de Oriximiná. Nas demais, as parcerias estabelecidas com a Seduc e com as Secretarias Municipais de Educação foram necessárias para que os servidores da universidade tivessem um local para trabalhar e para que as turmas do PARFOR pudessem funcionar.

\section{Análise e apresentação dos resultados}

A análise é um ato de desmembrar o objeto de estudo em partes ou agrupamentos para estudar sua natureza, sua função e ou seu significado. Neste trabalho, os dados coletados na fase de levantamento bibliográfico e na pesquisa documental foram organizados e sistematizados. A análise foi desenvolvida com o intuito de organizar as informações obtidas durante a realização da pesquisa para maximizar as relações que podem ser estabelecidas entre os dados documentais.

O Plano Nacional de Formação de Professores da Educação Básica - PARFOR teve resultados expressivos quando analisados de maneira geral. Entre os anos de 2009 e 2015, foram 103 (cento e três) Instituições de Ensino participantes, com funcionamento de turmas em 510 (quinhentos e dez) municípios polos, totalizando 3.300 (três mil e trezentos) municípios atendidos, num total de 2.903 (duas mil novecentos e três) turmas em todo o território nacional (BRASIL, 2018).

Em todo o território nacional, temos um total de 94.727 (noventa e quatro mil, setecentos e vinte e sete) professores/alunos que ingressaram no PARFOR. Destes, apenas 44.843 (quarenta e quatro mil, oitocentos e quarenta e três) concluíram as graduações ofertadas no programa, o que corresponde a 47,3\% da totalidade. A pesquisa realizada no SIGAA da UFOPA, em agosto do ano de 2019, permitiu a elaboração da tabela 1, que traz um panorama geral da quantidade de turmas e alunos que ingressaram no 
PARFOR da UFOPA entre os anos de 2010 e 2013, anos em que houve ingresso de alunos na IES.

Tabela 1 - Dados gerais de ingresso do PARFOR na UFOPA

\begin{tabular}{|c|c|c|c|c|c|}
\hline \multicolumn{6}{|c|}{ CURSO - LICENCIATURA INTEGRADA EM BIOLOGIA E QUÍMICA } \\
\hline MUNICÍPIO & 2010 & 2011 & 2012 & 2013 & $\begin{array}{l}\text { TOTAL POR } \\
\text { MUNICÍPIO }\end{array}$ \\
\hline ALENQUER & 42 & 32 & 42 & - & 116 \\
\hline ALMEIRIM & 31 & - & - & - & 31 \\
\hline ITAITUBA & - & - & 28 & - & 28 \\
\hline JURUTI & 34 & - & - & - & 34 \\
\hline MONTE ALEGRE & 40 & - & - & - & 40 \\
\hline ORIXIMINÁ & 19 & - & - & - & 19 \\
\hline ÓBIDOS & 30 & 19 & - & - & 49 \\
\hline SANTARÉM & 29 & 28 & 31 & 40 & 128 \\
\hline TOTAL GERAL & 225 & 80 & 100 & 40 & 445 \\
\hline \multicolumn{6}{|c|}{ CURSO - LICENCIATURA INTEGRADA EM HISTÓRIA E GEOGRAFIA } \\
\hline MUNICÍPIO & 2010 & 2011 & 2012 & 2013 & $\begin{array}{l}\text { TOTAL POR } \\
\text { MUNICÍPIO }\end{array}$ \\
\hline ALENQUER & 41 & 51 & 40 & - & 132 \\
\hline ALMEIRIM & 31 & - & - & - & 31 \\
\hline ITAITUBA & 33 & - & 26 & - & 59 \\
\hline JURUTI & 40 & - & - & - & 40 \\
\hline MONTE ALEGRE & 47 & - & 33 & $23^{*}$ & 103 \\
\hline ORIXIMINÁ & 40 & - & 30 & - & 70 \\
\hline ÓBIDOS & 47 & 42 & 31 & - & 120 \\
\hline SANTARÉM & 41 & 37 & 43 & 34 & 190 \\
\hline TOTAL GERAL & 320 & 133 & 200 & 92 & 745 \\
\hline \multicolumn{6}{|c|}{ CURSO - LICENCIATURA INTEGRADA EM LETRAS PORTUGUÊS E INGLÊS } \\
\hline MUNICÍPIO & 2010 & 2011 & 2012 & 2013 & $\begin{array}{l}\text { TOTAL POR } \\
\text { MUNICÍPIO }\end{array}$ \\
\hline ALENQUER & 43 & 37 & 44 & - & 124 \\
\hline ALMEIRIM & 50 & - & - & - & 50 \\
\hline ITAITUBA & 39 & 18 & 29 & 25 & 111 \\
\hline JURUTI & 42 & - & 33 & - & 75 \\
\hline MONTE ALEGRE & 43 & - & 39 & $24^{*}$ & 106 \\
\hline ORIXIMINÁ & 45 & 38 & 29 & - & 112 \\
\hline ÓBIDOS & 46 & 40 & - & - & 86 \\
\hline SANTARÉM & 47 & 42 & \begin{tabular}{l|l}
45 & 34 \\
\end{tabular} & \begin{tabular}{l|l}
41 & 42 \\
\end{tabular} & 251 \\
\hline TOTAL GERAL & 355 & 175 & 253 & 132 & 915 \\
\hline \multicolumn{6}{|c|}{ CURSO - LICENCIATURA INTEGRADA EM MATEMÁTICA E FÍSICA } \\
\hline MUNICÍPIO & 2010 & 2011 & 2012 & 2013 & $\begin{array}{l}\text { TOTAL POR } \\
\text { MUNICÍPIO }\end{array}$ \\
\hline ALENQUER & 44 & 33 & 26 & - & 103 \\
\hline ALMEIRIM & 36 & - & - & 15 & 51 \\
\hline ITAITUBA & 22 & 24 & 20 & 17 & 83 \\
\hline JURUTI & 40 & - & - & - & 40 \\
\hline MONTE ALEGRE & 48 & - & - & 22 & 70 \\
\hline ORIXIMINÁ & 27 & - & 26 & - & 53 \\
\hline ÓBIDOS & 50 & - & 35 & - & 85 \\
\hline
\end{tabular}




\begin{tabular}{|c|c|c|c|c|c|c|c|}
\hline SANTARÉM & 38 & 31 & \multicolumn{2}{|c|}{45} & 26 & 27 & 167 \\
\hline TOTAL GERAL & 305 & 88 & \multicolumn{2}{|c|}{153} & \multicolumn{2}{|c|}{106} & 652 \\
\hline \multicolumn{8}{|c|}{ CURSO - LICENCIATURA EM PEDAGOGIA } \\
\hline MUNICÍPIO & 2010 & 2011 & \multicolumn{2}{|c|}{2012} & \multicolumn{2}{|c|}{2013} & $\begin{array}{l}\text { TOTAL POR } \\
\text { MUNICÍPIO }\end{array}$ \\
\hline ALENQUER & 43 & 46 & 41 & 41 & \multicolumn{2}{|c|}{-} & 171 \\
\hline ALMEIRIM & 53 & - & \multicolumn{2}{|c|}{-} & \multicolumn{2}{|c|}{31} & 84 \\
\hline ITAITUBA & 31 & 31 & \multicolumn{2}{|c|}{-} & \multicolumn{2}{|c|}{31} & 93 \\
\hline JURUTI & 45 & 21 & \multicolumn{2}{|c|}{31} & \multicolumn{2}{|c|}{33} & 130 \\
\hline MONTE ALEGRE & 41 & 27 & \multicolumn{2}{|c|}{-} & \multicolumn{2}{|c|}{-} & 68 \\
\hline ORIXIMINÁ & 48 & 46 & \multicolumn{2}{|c|}{26} & \multicolumn{2}{|c|}{27} & 147 \\
\hline ÓBIDOS & 50 & 44 & \multicolumn{2}{|c|}{45} & \multicolumn{2}{|c|}{28} & 167 \\
\hline SANTARÉM & 38 & 33 & \multicolumn{2}{|c|}{37} & 45 & 46 & 199 \\
\hline TOTAL GERAL & 349 & 289 & \multicolumn{2}{|c|}{180} & \multicolumn{2}{|c|}{241} & 1.059 \\
\hline \multicolumn{8}{|c|}{ DADOS GERAIS DO PARFOR/UFOPA } \\
\hline \multicolumn{7}{|c|}{ TOTAL DE INGRESSANTES NO ANO DE 2010} & 1.554 \\
\hline \multicolumn{7}{|c|}{ TOTAL DE INGRESSANTES NO ANO DE 2011} & 765 \\
\hline \multicolumn{7}{|c|}{ TOTAL DE INGRESSANTES NO ANO DE 2012} & 886 \\
\hline \multicolumn{7}{|c|}{ TOTAL DE INGRESSANTES NO ANO DE 2013} & 611 \\
\hline \multicolumn{7}{|c|}{ TOTAL GERAL DE INGRESSANTES } & 3.816 \\
\hline
\end{tabular}

* Turma cadastrada no SIGAA da UFOPA, mas que não se iniciou por não atingir o número mínimo de 25 professores/alunos.

Fonte: SIGAA/UFOPA (2019), adaptado pelo autor (2019).

As informações da tabela 2 mostram o status dos alunos do PARFOR na Universidade Federal do Oeste do Pará até agosto do ano de 2019.

Tabela 2 - Status no SIGAA da UFOPA até agosto de 2019

\begin{tabular}{l|c}
\hline \multicolumn{1}{c}{ STATUS NO SIGAA/UFOPA (AGOSTO DE 2019) } \\
\hline TOTAL DE PROFESSORES/ALUNOS COM STATUS - CONCLUÍDO & 2.986 \\
\hline TOTAL DE PROFESSORES/ALUNOS COM STATUS - ATIVO & 602 \\
\hline TOTAL DE PROFESSORES/ALUNOS COM STATUS - FORMANDO & $\mathbf{2 1 6}$ \\
\hline TOTAL DE PROFESSORES/ALUNOS COM STATUS - CANCELADO & 3.816 \\
\hline TOTAL
\end{tabular}

Fonte: SIGAA/UFOPA (2019), adaptado pelo autor (2019).

Os dados obtidos nas tabelas 1 e 2 mostram que ingressaram um total de 3.816 (três mil, oitocentos e dezesseis) professores/alunos dos quais 2.986 (dois mil, novecentos e oitenta e seis) concluíram a graduação, correspondendo a $78,2 \%$ de efetividade, ou seja, o PARFOR na UFOPA mostrou-se bastante eficiente em sua execução, muito acima da média nacional de $47,3 \%$. 
O mesmo levantamento mostra que apareciam com status "Ativo" no SIGAA da UFOPA um total de 602 (seiscentos e dois) professores/alunos, os quais estão apenas aguardando o prazo estabelecido no regimento de graduação da universidade para serem jubilados, ou seja, terem seus vínculos cancelados. Também aparecem 216 (duzentos e dezesseis) com status "Cancelado" e mais 12 (doze) com status "Formando", os quais só precisam fazer a outorga de grau para finalizar seu curso de licenciatura.

A taxa de evasão (número de alunos com status "Cancelado" dividido pelo número total de ingressantes) é de 5,6\%, muito abaixo da média nacional que é de $22 \%$ nas turmas de licenciatura, conforme dados do INEP/MEC do ano de 2015. Considerando que não há mais turmas do PARFOR em funcionamento (nesta modalidade) na UFOPA, os alunos com status "Ativo" estão aguardando somente serem jubilados para terem seus status atualizados no SIGAA para "Cancelado". Com isso, pode-se afirmar que, somando o número de professores/alunos com status "Cancelado" com os de status "Ativo", há uma taxa de evasão de $21,4 \%$, condizente com a média nacional.

A matriz de dados obtida no SIGAA da UFOPA também mostra que, apesar da grande oferta de turmas, algumas não alcançaram o número mínimo de professores/alunos matriculados e, consequentemente, não foram iniciadas. Outro item que pode ser destacado é que a quantidade de alunos por turma não foi a ideal, ou seja, a quantidade de professores/alunos que ingressaram mostra que as turmas iniciaram com vagas sobrando, subutilizando o potencial de alcance do PARFOR na UFOPA e dificultando sua efetiva eficácia.

Verificou-se também, com base nos dados da pesquisa, que houve uma demanda maior por turmas no município de Santarém, uma vez que das 20 (vinte) previstas, foram ofertadas 25 (vinte e cinco), ou seja, 05 (cinco) a mais. Isso é um indicativo de que havia demanda de professores/alunos suficiente para que se justificasse a abertura de duas turmas de um mesmo curso no mesmo ano e na mesma localidade. Ainda sobre o município de Santarém, mesmo com um número maior de turmas do que o previsto, a quantidade de alunos que ingressou ficou muito abaixo do que poderia haver, o que mostra que algumas das turmas ingressantes estavam com a capacidade bem abaixo do ideal, confirmando a ideia de subutilização do potencial de alcance do PARFOR na UFOPA. 
Analisando o total geral das turmas possíveis e ofertadas, vê-se que havia sim uma grande necessidade regional de oferta de cursos do PARFOR, uma vez que 105 turmas foram abertas na UFOPA. Isso mostra também que PARFOR poderia alcançar uma quantidade bem maior de professores/alunos, visto que em vários municípios as turmas iniciarem bem aquém da sua capacidade máxima. Também pode ser destacado que em função do público-alvo do programa serem os docentes em exercício, outros profissionais ficaram de fora, apesar do interesse e necessidade de qualificação.

Os dados coletados também mostraram que a maioria dos professores/alunos que ingressaram no PARFOR na UFOPA está entre as faixas etárias de 30 a 39 anos. Verificouse que 2.694 (dois mil, seiscentos e noventa e quatro) são do gênero feminino o que corresponde a $70,6 \%$ da totalidade. Ou seja, a maioria dos profissionais que atuavam na docência, e que ainda não possuíam graduação, eram mulheres.

\section{Considerações finais}

A implantação de programas que fomentem a formação de professores para atuarem no ensino básico é importante para a melhoria da qualidade da educação brasileira. O Plano Nacional de Formação de Professores da Educação Básica - PARFOR, neste contexto, aparece como um dos programas do governo federal com maior alcance e êxito entre os que foram ofertados.

O PARFOR foi instituído para atender a formação inicial e continuada dos professores da Educação Básica em todo o território brasileiro e formou uma quantidade muito significativa de profissionais. Desde o ano de 2010, a Universidade Federal do Oeste do Pará - UFOPA atua na formação, em nível de graduação, de professores das redes públicas de educação por meio do PARFOR. Ou seja, o PARFOR na UFOPA alcançou resultados expressivos, formando mão de obra qualificada para atender ao que se pede na LDBEN.

Esses profissionais, agora com formação adequada, estão aptos a contribuir de maneira expressiva para a melhoria dos indicadores de qualidade da educação em todos os municípios da Região Sudoeste do Estado do Pará. Apesar da certeza de que este 
estudo apresenta limitações, espera-se que as reflexões aqui expostas apontem para novas possibilidades de pesquisa relacionadas ao PARFOR.

\section{Referências}

BARRETO, Eliane Gracy Lemos; COLARES, Anselmo Alencar. O PARFOR na Universidade Federal do Oeste do Pará (UFOPA): perspectivas para a melhoria na práxis pedagógica. Revista HISTEDBR On-line, Campinas, n. 71, p. 308-333, mar. 2017 - ISSN: 1676-2584. 2017. Disponível em: https://periodicos.sbu.unicamp.br/ojs/index.php/ histedbr/article/view/8645335. Acesso em: 02 ago. 2019.

BASTOS, Ana Fanny Benzi de Oliveira. Análise da implementação do plano nacional de formação de professores da educação básica em estados da região Norte do Brasil. 2015. 224 f. Tese (Doutorado em Educação) - Universidade Estadual de Campinas, Campinas, 2015.

BASTOS, Carmem Célia Barradas; ZANARDINI, Isaura Monica Souza. O PARFOR e a formação de professores da educação básica. Porto Alegre: Evangraf: UNIOESTE, 2014.

BRASIL. Ministério da Educação (MEC). Proposta de diretrizes para a formação inicial de professores da educação básica, em cursos de nível superior. Brasília, DF: Ministério da Educação, 2000. Disponível em: http://portal.mec.gov.br/cne/arquivos/pdf/basica.pdf. Acesso em: 30 ago. 2018.

BRASIL. Decreto n 6.755 de 29 de janeiro de 2009. Institui a política nacional de formação de profissionais do magistério da educação básica, disciplina a atuação da coordenação de aperfeiçoamento de pessoal de nível superior - CAPES no fomento a programas de formação inicial e continuada, e dá outras providências. Brasília, DF: Câmara Legislativa, 2009. Disponível em: https://www2.camara.leg.br/legin/fed/decret/2009/decreto-6755-29janeiro-2009-585786-publicacaooriginal-109115-pe.html. Acesso em: 23 fev. 2019.

BRASIL. Relatório de Gestão do exercício de 2016: CAPES. Brasília, DF: Ministério da Educação, 2017. 
BRASIL. CAPES. Plano nacional de formação de professores da educação básica -

PARFOR. Brasília, DF: CAPES, 2018. Disponível em: http://www.capes.gov.br/educacaobasica/parfor. Acesso em: 20 jul. 2019.

CARVALHO, Ednea do Nascimento. A interiorização do ensino superior na Amazônia: o caso de Santarém no oeste do Pará - 1985 a 2010. 2014. 265 f. Tese (Doutorado Acadêmico em Geografia) - Universidade Estadual do Ceará, Fortaleza, 2014.

COSTA, Maria Raimunda Santos da. Relatório Geral do Parfor - 2015 a 2017. Santarém: Universidade Federal do Oeste do Pará, ago. 2017.

DEB - Diretoria de Formação de Professores da Educação Básica. Relatório de Gestão do Parfor 2009 - 2013. Brasília DF: DEB, 2013.

INSTITUTO NACIONAL DE ESTUDOS E PESQUISAS EDUCACIONAIS ANISIO TEIXEIRA INEP. Censo do professor 1997: perfil dos docentes de Educação Básica. Brasília, DF: Inep, 1999.

INSTITUTO NACIONAL DE ESTUDOS E PESQUISAS EDUCACIONAIS ANISIO TEIXEIRA INEP. Sinopse estatística da educação básica 2015. Brasília: Inep, 2016. Disponível em: http://portal.inep.gov.br/sinopses-estatisticas-da-educacao-basica. Acesso em: 17 set. 2018.

KITAMURA, Indira Maria; SILVA, Rubicleis Gomes da. Expansão e configuração do ensino superior na região Norte Brasileira: uma análise do mercado educacional do Acre.

Espacios, Caracas, v. 36, n. 22, p. E-2, 2015. Disponível em:

http://www.revistaespacios.com/a15v36n22/153622E2.html. Acesso em: 07 set. 2018.

MARCONI, Marina de Andrade; LAKATOS, Eva Maria. Metodologia científica. 7. ed. São Paulo: Atlas, 2018.

MAUÉS, Olgaíses Cabral; CAMARGO, Arlete Maria Monte de. Marcos regulatórios nas políticas de formação e valorização docente pós-LDB. Revista Educação em Questão, Natal, v. 42, n. 28, p. 149-174, jan./abr. 2012.

NÓVOA, Antônio. Para uma formação de professores construída dentro da profissão. Revista Educación, Madrid, n. 350, p. 203-218, set./dez. 2009. Disponível em: http://www.revistaeducacion.educacion.es/re350/re350_ogpor.pdf. Acesso em: 10 mar. 2019.

PÁDUA, Elisabete Matallo Marchesini de. Metodologia da pesquisa: abordagem teóricoprática. 17. ed. Campinas: Papirus Editora. 2012

PARÁ. Secretaria de Estado de Educação. Protocolo SEDUC-IES. Plano decenal de formação docente do Estado do Pará. Belém: SEDUC-IES, 2009. Disponível em: http://www6.seduc.pa.gov.br/planodeformacao/arquivos. Acesso em: 15 set. 2018. 
SIGAA. Sistema Integrado de gestão de atividades acadêmicas. [Belém]: Universidade Federal do Oeste do Pará. 2018.

VASCONCELOS, Elizandra Rego de. A formação de professores na Amazônia e as dimensões socioambientais: um estudo sobre o Parfor. 2016. 248 f. Tese (Doutorado em Educação Científica e Tecnológica) - Universidade Federal de Santa Catarina, Florianópolis, 2016.

Recebido em: 13/06/2020 Revisões requeridas: $15 / 02 / 2021$ Aprovado em: 01/03/2021

Universidade do Estado de Santa Catarina - UDESC Programa de Pós-Graduação em Educação - PPGE Revista Linhas

Volume 22 - Número 49 - Ano 2021 revistalinhas@gmail.com 